\title{
Magnetic Colloidosomes Derived from Nanoparticle Interfacial Self-
}

\section{Assembly}

Hongwei Duan, ${ }^{\dagger}$ Dayang Wang, ${ }^{\dagger, *}$ Nelli S. Sobal, ${ }^{\ddagger}$ Michael Giersig, ${ }^{\ddagger}$ Dirk G. Kurth, ${ }^{\dagger}$ and Helmuth Möhwald ${ }^{\dagger}$

${ }^{\dagger}$ Max Planck Institute of Colloids and Interfaces, D-14424, Potsdam, Germany

${ }^{\ddagger}$ Center of Advanced European Studies and Research, D-53175, Bonn, Germany

\section{Supporting Information:}

\section{Experimental section}

$4.0 \mathrm{~nm}, 5.0 \mathrm{~nm}$ and $8.0 \mathrm{~nm} \mathrm{Fe}_{3} \mathrm{O}_{4} \mathrm{NPs}$, stabilized with oleic acid, were prepared following the method reported by Sun and coworkers. ${ }^{1}$ 2-bromo-2-methylpropionic acid (BMPA)-capped $\mathrm{Fe}_{3} \mathrm{O}_{4} \mathrm{NPs}$ were prepared as described previously. ${ }^{2}$ Briefly, $5 \mathrm{ml}$ toluene dispersion of $\mathrm{Fe}_{3} \mathrm{O}_{4}$ NPs was incubated with $5 \mathrm{ml}$ toluene solution of $1.67 \mathrm{~g}$ BMPA for 2 days. The subsequent removal of excess BMPA by centrifugation yielded BMPA-capped NPs. CdTe NPs, stabilized by thioglycolic acid, were prepared as described elsewhere. ${ }^{3}$ The CdTe NP sizes were altered by the reflux period; $0.5 \mathrm{~h}$ for $2.8 \mathrm{~nm}$ and $72 \mathrm{~h}$ for $4.0 \mathrm{~nm}$.

$1 \mathrm{mg}$ BMPA-capped $\mathrm{Fe}_{3} \mathrm{O}_{4} \mathrm{NPs}$ of $4.0 \mathrm{~nm}, 5.0 \mathrm{~nm}$ or $8.0 \mathrm{~nm}$ in size was dissolved in $0.8 \mathrm{~mL}$ toluene and then $0.5 \mathrm{~mL}$ water was added. After emulsification of this two-phase system by vigorous shaking for $10 \mathrm{~min}$, water-in-toluene droplets stabilized with $\mathrm{Fe}_{3} \mathrm{O}_{4}$ NPs, colloidosomes, were obtained. The amounts of 4.0, 5.0, and $8.0 \mathrm{~nm} \mathrm{Fe} \mathrm{O}_{4} \mathrm{NPs}$ used for emulsification of $0.5 \mathrm{ml}$ water, determined by UV-Vis absorption spectroscopy (Cary $50 \mathrm{UV}$-visible spectrophotometer), are about $0.5,0.5$, and $1.0 \mathrm{mg}$. In order to gelate

\footnotetext{
To whom the correspondence should be addressed. Fax: +49 331567 9202. Email: dayang@mpikggolm.mpg.de
} 
aqueous phases, $7.5 \mathrm{mg}$ agarose was dissolved in $0.5 \mathrm{~mL}$ water or aqueous solutions of $2.8 \mathrm{~nm}$ or $4.0 \mathrm{~nm}$ CdTe NPs at $70{ }^{\circ} \mathrm{C}$, forming $1.5 \mathrm{wt} \%$ solutions. After emulsifying them in $\mathrm{Fe}_{3} \mathrm{O}_{4} \mathrm{NP}$ toluene dispersions by vigorous shaking for $10 \mathrm{~min}$ at $70{ }^{\circ} \mathrm{C}$, water-intoluene droplets were obtained. After cooling to room temperature, the aqueous phase turned out gelated, thus forming colloidosomes with hydrogel cores. These colloidosomes were collected by an external magnetic field, washed with ethanol three times and dispersed in water.

TEM images were obtained by a Zeiss EM 912 Omega microscope at an acceleration voltage of $120 \mathrm{kV}$. The ultrathin sections for TEM imaging were obtained by slicing colloidosomes with gel cores by using a Leica ultracut UCT ultramicrotome after embedding them in LR-white resin. Confocal images were implemented by a Leica confocal laser scanning microscope with a $10 \times$ objective. The numerical aperture was set at 1.4 and the excitation wavelength at $480 \mathrm{~nm}$.

(1) Sun, S. H.; Zeng, H.; Robinson, D. B.; Raoux, S.; Rice, P. M.; Wang, S. X.; Li, G. X. J. Am. Chem. Soc. 2004, 126, 273.

(2) Duan, H.; Wang, D.; Kurth, D. G.; Möhwald, H. Angew. Chem. Int. Ed. 2004, 43, 5639.

(3) Zhang, H.; Cui, Z.; Wang, Y.; Zhang, K.; Ji, X.; Lu, C.; Yang, B.; Gao, M. Adv. Mater. 2003, 15, 777. 

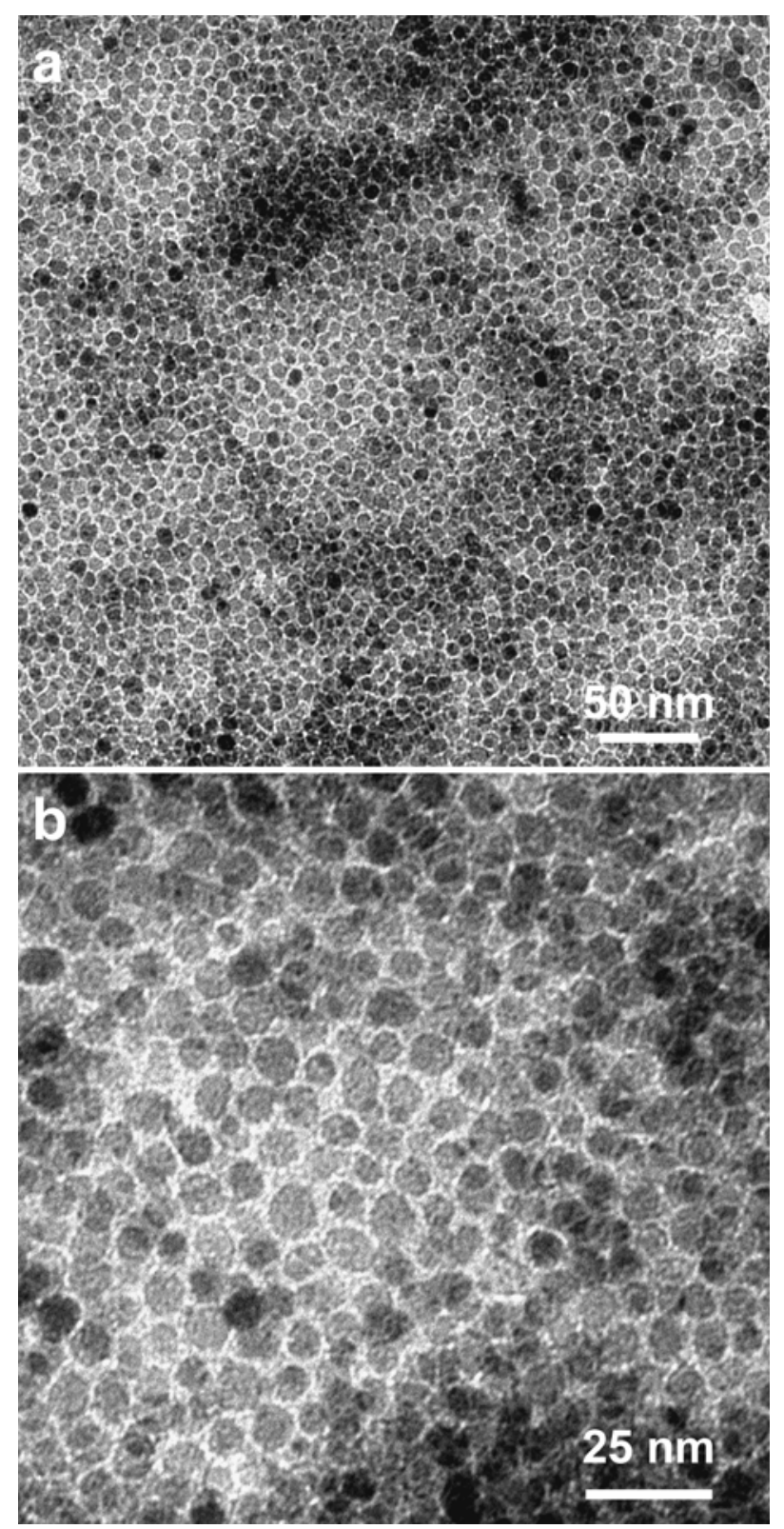

Figure S1. High (a) and low (b) magnification TEM images of the broken areas of dried $8.0 \mathrm{~nm} \mathrm{Fe}_{3} \mathrm{O}_{4} \mathrm{NP}$ Colloidosomes, in which the NP monolayer of a short-range ordered packing array is clearly observed. 


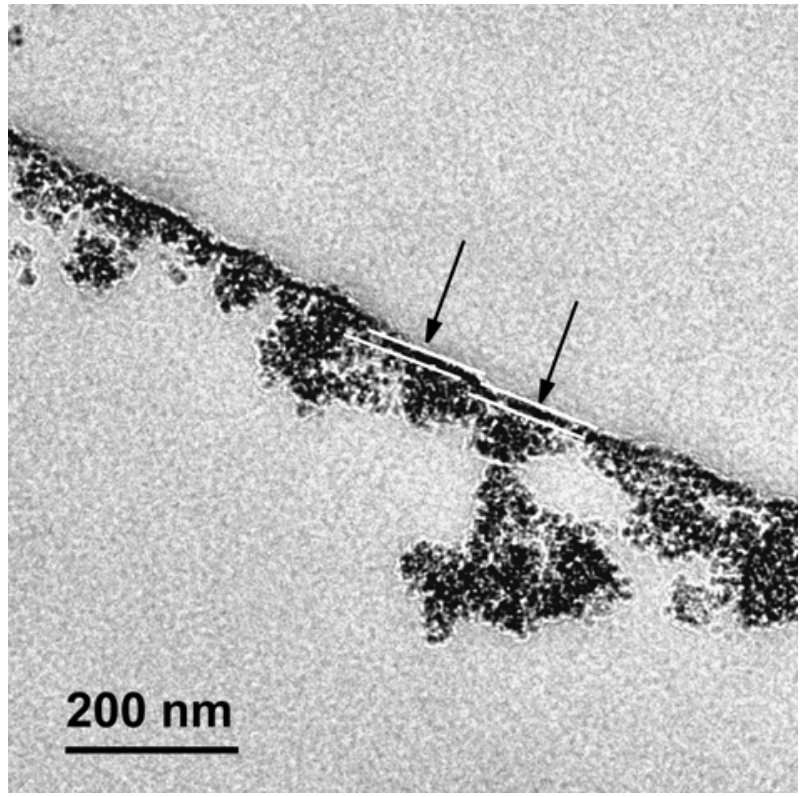

Figure S2. TEM image of an ultrathin section of a dried $8.0 \mathrm{~nm}$ colloidosome containing an agarose core. The colloidosome shell is indicated by arrows. Due to the collapse of the colloidosomes after drying, there exist a lot of folds and creases on dried colloidosomes, so fragments of close-packed NP aggregates are also visible in this picture. 


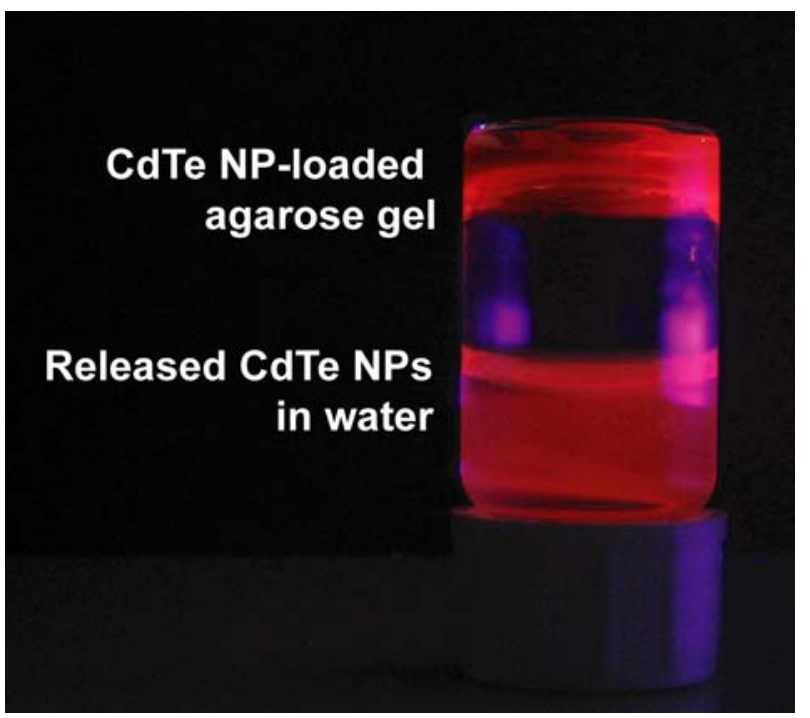

Figure S3. Fluorescence photograph of a reversed glass vial containing an agarose gel loaded with $4.0 \mathrm{~nm}$ CdTe NP (at the tube bottom) and water (at the tube top). After water was added atop the CdTe NP-loaded hydrogel in $1 \mathrm{~min}$, the glass tube was laid bottomup, in which both the hydrogel and water exhibit red luminescence, suggesting the loaded NPs were released out of the hydrogel. 


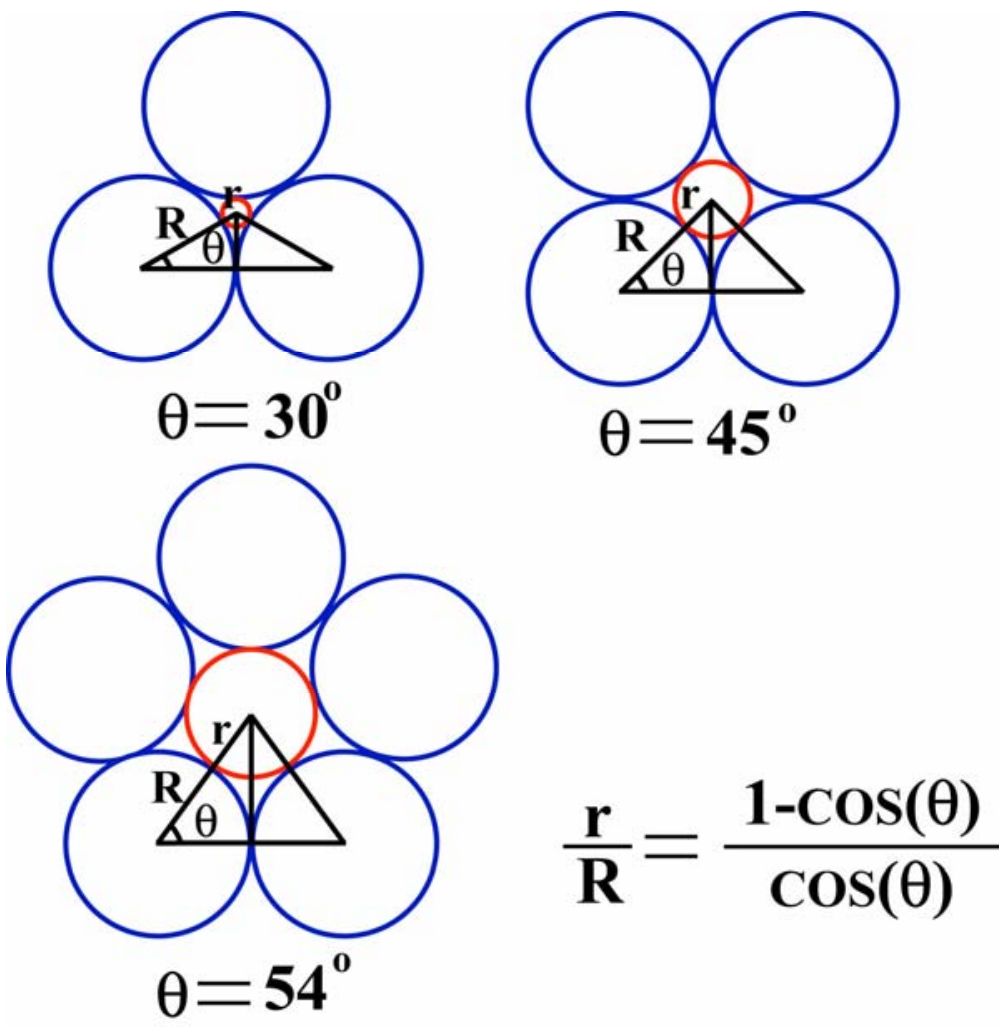

Scheme S1. Schematic illustration of interstices within hexagonal, cubic and pentagonal arrays of NPs assembled in the colloidosome shells and the equation for evaluation of the cutoffs of the colloidosomes. 